\title{
Shotgun Mechanisms for Common-Value Partnerships: The Unassigned-Offeror Problem
}

\section{Citation}

Claudia M. Landeo \& Kathryn E. Spier, Shotgun Mechanisms for Common-Value Partnerships: The Unassigned-Offeror Problem, 121 Econ. Letters 390 (2013).

\section{Published Version}

http://www.sciencedirect.com/science/article/pii/S0165176513004230

\section{Permanent link}

http://nrs.harvard.edu/urn-3:HUL.InstRepos:12967824

\section{Terms of Use}

This article was downloaded from Harvard University's DASH repository, and is made available under the terms and conditions applicable to Open Access Policy Articles, as set forth at http:// nrs.harvard.edu/urn-3:HUL.InstRepos:dash.current.terms-of-use\#OAP

\section{Share Your Story}

The Harvard community has made this article openly available.

Please share how this access benefits you. Submit a story.

Accessibility 


\title{
HARVARD
}

JOHN M. OLIN CENTER FOR LAW, ECONOMICS, AND BUSINESS

\author{
SHOTGUN MECHANISMS FOR COMMON-VALUE \\ PARTNERSHIPS: THE UNASSIGNED-OFFEROR PROBLEM
}

Claudia M. Landeo

Kathryn E. Spier

Discussion Paper No. 754

$09 / 2013$

Harvard Law School

Cambridge, MA 02138

This paper can be downloaded without charge from:

The Harvard John M. Olin Discussion Paper Series: http://www.law.harvard.edu/programs/olin_center/

The Social Science Research Network Electronic Paper Collection:

http://ssrn.com/ 
[Economics Letters, forthcoming.]

\title{
Shotgun Mechanisms for Common-Value Partnerships: The Unassigned-Offeror Problem
}

\author{
Claudia M. Landeo*and Kathryn E. Spier ${ }^{\dagger}$
}

September 20, 2013

\begin{abstract}
Shotguns clauses are commonly included in the business agreements of partnerships and limited liability companies (LLCs), but the role of offeror typically remains unassigned. In a common-value, one-sided asymmetric information setting, unequal and inefficient outcomes occur with an unassigned offeror. Experimental results are aligned with our theory.
\end{abstract}

KEYWORDS: Business Deadlock; Shotgun Mechanisms; Asymmetric Information; Experiments.

JEL Classification: K40, C72, C90, D82.

\footnotetext{
${ }^{*}$ University of Alberta Economics Department. Henry Marshall Tory Building 7-25, Edmonton, AB T6G 2H4. Canada. landeo@ualberta.ca.

${ }^{\dagger}$ Harvard Law School and NBER. 1575 Massachusetts Ave., Cambridge, MA 02138. kspier@law.harvard.edu, tel.617-496-0019; corresponding author.
} 


\section{Introduction}

Deadlocks or impasses between joint owners concerning fundamental business decisions can paralyze closely-held companies including partnerships and LLCs. When a business relationship deteriorates to the point where the joint owners cannot be reconciled, it may become necessary to dissolve the business venture and/or to dissociate one (or more) of the owners. Placing an accurate value on the business assets - a necessary step in finalizing a business divorce - can be difficult, especially when the best wisdom concerning the value of the assets is in the minds of the business owners themselves, and an outside market for the assets does not exist.

In a shotgun mechanism, one owner names a single buy-sell price and the other owner then decides whether to sell or buy at that price. Shotgun provisions are fairly common in the private business agreements of partnerships and LLCs. ${ }^{1}$ In the words of Judge Frank Easterbrook, "[t]he possibility that the person naming the price can be forced either to buy or to sell keeps the first mover honest." ${ }^{2}$ In private contractual settings, the identity of the offeror is typically not specified, i.e., the role of offeror remains unassigned.

Shotgun mechanisms are sometimes mandated by judges when overseeing business divorce proceedings. In Kinzie $v$. Dells, a recent business deadlock case from Canada, ${ }^{3}$ the presiding judge describes the appropriate assignment of the role of offeror: "In a 'shot gun' sale, the court must determine the party who will make the first offer. Normally, the party who is in the best position to assess the value of the business and determine the fair market value is ordered to make the initial offer."

This article theoretically and experimentally studies shotgun mechanisms in a common-value, one-sided asymmetric information setting. When the role of offeror remains unassigned, coordination failures arise and unequal and inefficient outcomes are obtained. ${ }^{4}$ Equitable and efficient outcomes are achieved only when the role of

\footnotetext{
${ }^{1}$ These mechanisms may also be referred to as Texas shootouts, Russian roulette, Chinese wall clauses, put-call options, dynamite or candy bar methods, or simply buy-sell mechanisms (Carey, 2005). See Crawford (1977), Che and Hendershott (2008), and De Frutos and Kittsteiner (2008). See also our previous work and the references cited there (Brooks et al., 2010).

${ }^{2}$ Valinote v. Ballis; 295, F3d. 666 (Ill. 2002).

${ }^{3}$ Kinzie v. Dells 2010 BCSC 1360 (Can. B.C.). Shotgun mechanisms are rare in the United States, but see Fulk v. Washington Serv. Assocs. No. 17747-NC, 2002 BL 1389 (Del. Ch. June 21, 2002). See Landeo and Spier (forthcoming, (a) and (b)).

${ }^{4}$ Landeo and Spier (forthcoming, (a) and (b)) and Brooks et al. (2010) do not study shotgun
} 
offeror is assigned to the better-informed party. It may be difficult for the owners to adequately assign the role of offeror in the shotgun provision. The identity of the better-informed party in the event of deadlock is frequently unforeseeable ex ante. In contrast, the ex post feature of the judicial implementation of the mechanism might allow courts to identify the better-informed party and properly assign the role of offeror.

\section{Theoretical Framework}

Suppose that two co-venturers ${ }^{5}$ own equal stakes in a firm with uncertain value $x$, which is drawn from a uniform distribution on the interval $\left[x_{L}, x_{H}\right] . \bar{x}$ is the average value. The informed player (Owner 1) knows the true value of $x$; the uninformed owner (Owner 2) does not observe the value. Thus, this game has one-sided asymmetric information with common values. We assume that there is a business deadlock; the assets will be more valuable if ownership is consolidated. Resolving the deadlock will create an additional $a$ of value, so after the consolidation of ownership the assets are worth $x+a \in\left[x_{L}+a, x_{H}+a\right]$. In a shotgun mechanism, one owner names a single buy-sell price, which we represent as $p$, and the other owner is compelled to either buy or sell shares at that named price. If Owner $i$ purchases Owner $j$ 's stake for price $p$, the payoff for Owner $i$ is $x+a-p$ and the payoff for Owner $j$ is $p$. If the business remains deadlocked, each owner receives $\frac{x}{2}$. The equilibrium concept is the perfect Bayesian equilibrium.

We will show that when the role of offeror is unassigned, inefficient outcomes may result as a consequence of a coordination failure between the owners. To understand this outcome, it is useful to restate our previous findings regarding the equilibria with assigned offerors (Brooks et al., 2010). ${ }^{6}$ Proposition 1 first characterizes the unique fully-separating equilibrium of the shotgun mechanism when the informed party, Owner 1, makes the buy-sell offer. Owner 1's buy-sell offer fully reveals Owner 1 's type $x$ and leads to an equitable division of the surplus. ${ }^{7}$ Second, it outlines the

mechanisms with unassigned offerors. In a different environment, De Frutos and Kittsteiner (2008) theoretically explore an auction mechanism for assigning the role of offeror.

${ }^{5}$ According to Hauswald and Hege (2006), $80 \%$ of all joint ventures incorporated in the U.S. between 1985 and 2000 are two-partner joint ventures.

${ }^{6}$ See our previous work (Brooks et al., 2010) for formal discussion and proofs.

${ }^{7}$ There also exists a pooling equilibrium where Owner 1 offers $p(x)=\frac{\bar{x}+a}{2}$ and Owner 2 mixes 
equilibrium of the shotgun mechanism when the uninformed party, Owner 2, makes the buy-sell offer. Owner 2's offer reflects the average value of the assets rather than the realized value ( $\operatorname{since} x$ is known only to Owner 1 ), and Owner 1 receives a greater equilibrium share of the surplus than Owner 2.

PROPOSITION 1: First, suppose Owner 1 (the informed party) is assigned the role of offeror. There is a unique fully-separating equilibrium where Owner 1 offers $p_{1}(x)=\frac{x+a}{2}$ and Owner 2 randomizes between buying and selling with equal probability. The ex ante expected payoffs of each owner are $\frac{\bar{x}+a}{2}$. Second, suppose Owner 2 (the uninformed party) is assigned the role of offeror. In equilibrium, Owner 2 offers $p_{2}=\frac{\bar{x}+a}{2}$. Owner 1 sells his stake to Owner 2 when $x<\bar{x}$ and buys Owner 2's stake when $x \geq \bar{x}{ }^{8}$ The ex ante expected payoffs of Owner 1 and Owner 2 are $\frac{\bar{x}+a}{2}+\frac{x_{H}-x_{L}}{8}$ and $\frac{\bar{x}+a}{2}-\frac{x_{H}-x_{L}}{8}$, respectively.

We now consider the shotgun mechanism with an unassigned offeror. In this mechanism, the two owners have the option (but not the obligation) to make simultaneous buy-sell offers. If only one offer is made, the receiver is compelled to either buy the stake of the offeror or to sell his own stake. If two offers are made, a coin flip determines which of the two offers applies. The results of our first two propositions suggest a potential conflict between the two owners in this setting. The uninformed player, Owner 2, would prefer that Owner 1 makes the buy-sell offer since $p_{1}(x)=\frac{x+a}{2}$ gives Owner 2 an equitable share of the surplus. Owner 1 would prefer that Owner 2 make the buy-sell offer, since receiving $p_{2}=\frac{\bar{x}+a}{2}$ will allow Owner 1 to exploit his informational advantage.

When the gains from consolidation, $a$, are sufficiently large, then there are multiple equilibria. In one equilibrium, Owner 1 makes a perfectly-revealing and equitable offer $p_{1}(x)=\frac{x+a}{2}$ and Owner 2 mixes between accepting in rejecting (as in Proposition 1). In a second equilibrium, Owner 2 makes an offer $p_{2}=\frac{\bar{x}+a}{2}$ and Owner 1 buys when $x$ is high and sells if $x$ is low (as in Proposition 1). Interestingly, there is also a mixed-strategy equilibrium where Owner 2 mixes between making an offer and does not make one, and Owner 1 offers $p_{1}=\frac{x+a}{2}$ if and only if his type, $x$, is sufficiently close to the average type $\bar{x}$. In this mixed-strategy equilibrium, it is between buying and selling with equal likelihood. The expected payoffs are the same as in the separating equilibrium.

${ }^{8}$ Here, we assume that the recipient buys when indifferent. 
possible that neither owner makes a buy-sell offer, leaving the gains from trade, $a$, unrealized. ${ }^{9}$ Proposition 2 characterizes the equilibria.

PROPOSITION 2: Suppose the role of offeror has not been assigned. If a < $\frac{x_{H}-x_{L}}{4}$ then Owner 1 (the informed party) makes a buy-sell offer and Owner 2 (the uninformed party) does not. If $a \geq \frac{x_{H}-x_{L}}{4}$ then:

(i) There is an equilibrium where Owner 1 (the informed party) makes an offer and Owner 2 does not;

(ii) There is an equilibrium where Owner 2 (the uninformed party) makes an offer and Owner 1 does not; and

(iii) There is a mixed-strategy equilibrium where Owner 2 (the uninformed party) offers $p_{2}=\frac{\bar{x}+a}{2}$ with probability $\theta$ and makes no offer with probability $1-\theta$. Owner 1 (the informed party) offers $p_{1}(x)=\frac{x+a}{2}$ when $x \in[\bar{x}-\Delta, \bar{x}+\Delta]$ and does not make an offer otherwise. The payoffs of Owner 1 and Owner 2 are $\frac{\bar{x}+a}{2}+$ $a\left(\theta-\frac{1}{2}\right)\left(1-\frac{2 \Delta}{x_{H}-x_{L}}\right)$ and $\frac{\bar{x}+a}{2}-a\left(\frac{1}{2}-\frac{\Delta}{x_{H}-x_{L}}\right)$, respectively. $\theta \in(0,1)$ and $\Delta \in$ $\left(0, \frac{x_{H}-x_{L}}{2}\right)$ exist and solve the following system of two equations: $2 \Delta^{2}-8 a \Delta=$ $\left(x_{H}-x_{L}\right)^{2}-4 a\left(x_{H}-x_{L}\right)$ and $\Delta=2 a(1-\theta) / \theta$.

PROOF. When $a<\frac{x_{H}-x_{L}}{4}$, remaining in the deadlock gives Owner 2 an expected payoff of $\frac{\bar{x}}{2}$ which is higher than what he would receive in the role of offeror, $\frac{\bar{x}+a}{2}-$ $\frac{x_{H}-x_{L}}{8}$ (see Proposition 1). So Owner 2 will refrain from making a buy-sell offer. Owner 1, on the other hand, could guarantee himself a payoff of $\frac{x+a}{2}>\frac{x}{2}$ by offering $p_{1}=\frac{x+a}{2}$. So Owner 1 makes a buy-sell offer in equilibrium.

Now consider $a>\frac{x_{H}-x_{L}}{4}$. Suppose Owner 2 offers $p_{2}=\frac{\bar{x}+a}{2}$ with probability $\theta$. Suppose $x<\bar{x}$, so Owner 1 would choose to sell when faced with this offer. If Owner 1 does not make an offer, his payoff is $(1-\theta)\left(\frac{x}{2}\right)+(\theta)\left(\frac{\bar{x}+a}{2}\right)$. If Owner 1 makes an offer $p_{1}=\frac{x+a}{2}$, his payoff is $\left(1-\frac{\theta}{2}\right)\left(\frac{x+a}{2}\right)+\left(\frac{\theta}{2}\right)\left(\frac{\bar{x}+a}{2}\right)$. Setting these expressions equal to each other verifies that Owner 1 is indifferent between making an offer and not making an offer when the asset value is $\bar{x}-\Delta$ where $\Delta=2 a(1-\theta) / \theta$. Similarly, one can establish indifference for Owner 1 between making an offer and not making one when the asset value is $\bar{x}+\Delta$.

Consider Owner 2's decision. If Owner 2 does not make an offer, his payoff is

\footnotetext{
${ }^{9}$ This outcome might also explain why privately-contracted shotgun clauses are rarely triggered. See Brooks et al. (2010).
} 


$$
\int_{x_{L}}^{\bar{x}-\Delta}\left(\frac{x}{2}\right) d F(x)+\int_{\bar{x}-\Delta}^{\bar{x}+\Delta}\left(\frac{x+a}{2}\right) d F(x)+\int_{\bar{x}+\Delta}^{x_{H}}\left(\frac{x}{2}\right) d F(x)
$$

where $d F(x)=\frac{d x}{x_{H}-x_{L}}$ (since $x$ is uniformly distributed). That is, when the value of $x$ is at the extremes then Owner 1 will refrain from making an offer and the deadlock will remain, giving Owner 2 a payoff of $\frac{x}{2}$. When $x \in[\bar{x}-\Delta, \bar{x}+\Delta]$, then Owner 1 offers $p_{1}=\frac{x+a}{2}$ and Owner 2 will receive a net payoff of $\frac{x+a}{2}$. Simplifying, Owner 2 's payoff is:

$$
\frac{\bar{x}}{2}+\frac{a \Delta}{\left(x_{H}-x_{L}\right)} .
$$

Rearranging this expression gives the expression for Owner 2's payoff in the proposition. Adding the expected payoffs for Owners 1 and 2 as stated in the proposition, one finds that their joint expected payoff is: $\bar{x}+a-a(1-\theta)\left(1-\frac{2 \Delta}{x_{H}-x_{L}}\right)$. That is, their joint payoff is $\bar{x}+a$, which is the efficient joint surplus, minus a loss, $a(1-\theta)\left(1-\frac{2 \Delta}{x_{H}-x_{L}}\right)$, reflecting the likelihood that neither owner makes an offer. This proves the expression for Owner 1's payoff in the proposition.

If Owner 2 offers $p_{2}=\frac{\bar{x}+a}{2}$ (which is an optimal offer for Owner 2 given Owner 1 's strategy) then Owner 2's expected payoff is

$$
\begin{gathered}
\int_{x_{L}}^{\bar{x}-\Delta}\left(x+a-\frac{\bar{x}+a}{2}\right) d F(x)+\int_{\bar{x}+\Delta}^{x_{H}}\left(\frac{\bar{x}+a}{2}\right) d F(x) \\
+\frac{1}{2} \int_{\bar{x}-\Delta}^{\bar{x}}\left(x+a-\frac{\bar{x}+a}{2}\right) d F(x)+\frac{1}{2} \int_{\bar{x}}^{\bar{x}+\Delta}\left(\frac{\bar{x}+a}{2}\right) d F(x) \\
+\frac{1}{2} \int_{\bar{x}-\Delta}^{\bar{x}+\Delta}\left(\frac{x+a}{2}\right) d F(x) .
\end{gathered}
$$

The first two terms reflect Owner 2's payoff when the asset value $x$ is in the extremes of the distribution so Owner 1 does not make a buy-sell offer. The second two terms reflect Owner 2's payoff when the asset value is in the middle of the distribution and Owner 2 wins the coin flip and makes the active offer (which happens with probability $\frac{1}{2}$ ). The last term reflects Owner 2's payoff in the middle of the distribution when Owner 1's offer, $p_{1}(x)=\frac{x+a}{2}$, is active (which happens with probability $\frac{1}{2}$ ). Combining and rearranging terms, this expression becomes:

$$
\frac{\left(x_{H}+3 x_{L}\right)}{8}+\frac{a}{2}+\frac{\Delta^{2}}{4\left(x_{H}-x_{L}\right)} .
$$


In equilibrium, Owner 2 is indifferent between making an offer and not making an offer. Setting these two simplified expressions equal to each other and rearranging terms gives $2 \Delta^{2}-8 a \Delta=\left(x_{H}-x_{L}\right)^{2}-4 a\left(x_{H}-x_{L}\right)$ (as in the proposition). This quadratic equation has two positive roots, one with $\Delta$ smaller than $2 a$ and one with $\Delta$ larger than $2 a$. Only the smaller of the two roots has the necessary property that $\Delta \in\left(0, \frac{x_{H}-x_{L}}{2}\right)$.

\section{Experimental Evidence}

This section reports the results from a series of experiments with human subjects paid according to their performance. We investigate whether the shotgun mechanism with an unassigned offeror generates inequitable and inefficient outcomes. ${ }^{10}$ We consider two treatments: Shotgun mechanisms with an unassigned offeror (NO), and Shotgun mechanisms with an informed offeror (IO). ${ }^{11}$

\subsection{Numerical Example}

Computational demands on the subjects are reduced by using a simple numerical example. We assume that two co-venturers, Owner 1 (the informed player) and Owner 2 (the uninformed player), own equal stakes in a firm with uncertain value $x$, which is drawn from a uniform distribution on the interval [ $\$ 400, \$ 1000]$. Due to business deadlock, consolidated ownership creates an additional value $a=\$ 200$. $^{12}$ Thus, the value of the business assets per owner under consolidation is equal to $(x+\$ 200) / 2 \in[\$ 300, \$ 600] .{ }^{13}$ In the mixed-strategy equilibrium of the unassigned-

\footnotetext{
${ }^{10}$ Kittsteiner et al. (2012) present an experimental study of privately-contracted shotgun and auction mechanisms in private-value settings.

${ }^{11}$ In a previous paper on judicial resolution of deadlocks (Landeo and Spier, forthcoming, (b)), we studied three conditions: shotguns with informed and uninformed offerors and private auction. We showed that the IO is equity superior to the other two mechanisms. We decided to use the data for the IO condition in our current study to construct the qualitative hypothesis regarding the effects of NO on the likelihood of equitable outcomes. The unassigned-offeror condition was not explored in our previous paper.

${ }^{12}$ The value of $a$ allows us to replicate the theoretical environment that triggers multiplicity of equilibria in the unassigned-offeror environment.

${ }^{13}$ The experimental setting satisfies the assumptions of the theory. To ensure control and replicability, only few labels are used to motivate the experimental environment.
} 
offeror environment (NO), the informed owner should decline to be the offeror for values of the business assets per owner under consolidation outside the interval [408,492], i.e., in $72 \%$ of the cases; the uninformed owner should be gun shy in $17 \%$ of the cases; and hence, both owners should be gun shy in $12 \%$ of the cases. Inefficient and unequal outcomes will occur under the mixed-strategy equilibrium of the NO environment. The hypotheses are as follows.

HYPOTHESIS 1: The shotgun mechanism with an unassigned offeror produces inefficient outcomes.

HYPOTHESIS 2: The shotgun mechanism with an unassigned offeror reduces the likelihood of equitable outcomes and the payoff for the uninformed owner (with respect to the shotgun mechanism with an informed offeror).

\subsection{Games and Sessions}

Subjects played 8 practice rounds and 16 actual rounds using networked computer terminals. ${ }^{14}$ Before the beginning of the first actual round, the computer randomly assigned a role to the subjects: Player 1 or Player 2 (Player 1, the informed player, was the offeror in the Informed Offeror condition, and both players were potential offerors in the unassigned-offeror condition). Before the beginning of each actual round, the computer also randomly formed pairs. ${ }^{15}$ Subjects were not paired with the same partner in any two immediately consecutive rounds. Then, the computer randomly chose the value of the business assets. ${ }^{16}$ This value was revealed only to Player $1^{17}$

In the shotgun mechanism with an informed-offeror condition (IO), the subjects played a two-stage game. In the first stage, the informed offeror made a buy-sell

\footnotetext{
${ }^{14}$ Undergraduate and graduate students at the University of Alberta were recruited from electronic bulletin boards. Players were completely anonymous to one another. Hence, this experimental environment did not permit the formation of reputations. The purpose of the practice rounds was to allow subjects to become familiar with the experimental environment. During the practice rounds, subjects experienced each role four times.

${ }^{15}$ Given the randomization process used to form pairs, and the diversity of offer categories and prices that subjects confronted, the sixteen actual rounds do not represent identical repetitions of the game. Consequently, we can treat each round as a one-shot experience.

${ }^{16}$ The computer got the realization of the value of the business assets under joint ownership from the interval [400,1000]. Only even integers were considered.

${ }^{17}$ Both players knew that Player 1 received this information. See instructions (Appendix).
} 
offer $p \geq 0$ to the other subject, who played the role of the offeree. In the second stage, the offeree was required to respond to the offer by either buying or selling at the named price. In the unassigned offeror condition (NO), Player 1 and Player 2 simultaneously decided whether to be the offeror and propose a buy-sell price. If both players decided to be the offeror, the computer randomly allocated the role of the offeror (with equal likelihood). The offeree then decided whether to buy or to sell at the proposed price. If neither player decided to be the offeror, joint ownership was preserved and the game ended.

We ran two sessions (90- and 120-minute sessions, for the IO and NO conditions, respectively; 36 subjects in total) at the University of Alberta School of Business computer laboratories. ${ }^{18}$ The subject pool (undergraduate and graduate students from the University of Alberta) received their monetary payoffs in cash (\$27 CAD game earnings, on average) at the end of the session. ${ }^{19}$ Our laboratory currency, the "token," was converted to Canadian dollars using a commonly-known exchange rate (427 tokens $=1$ Canadian dollar).

\section{$3.3 \quad$ Results}

\section{Data Summary}

As Figures 1 and 2 indicate, ${ }^{20}$ informed offerors' proposals made in the IO and NO conditions exhibited similar patterns: Offers increased with the value of the business assets, an expected result; and, more (less) equitable offers were observed for low(high) assets values, an unanticipated finding. Uninformed offerees' behavior followed the theory (buy rates equal to 44 and 45\%, in the IO and NO conditions, respectively). ${ }^{21}$ The uninformed offerors' proposals in the NO condition (Figure 3) were also aligned with the theory (mode offer equal to 450). As expected, informed offerees sold when asset values were lower than 450 (94\% of the cases) and bought

\footnotetext{
${ }^{18}$ The number of subjects and observations (number of pairs for the 16 rounds) per condition are 18 and 144, respectively.

${ }^{19}$ The participation fee was $\$ 10$ CAD.

${ }^{20}$ The figures include information about the observed offers, offers that produce equitable outcomes (Equitable Buy-Sell Offers), and offers predicted by the theory (Predicted Buy-Sell Offer). Finally, they include Fitted Values, i.e., predicted linear relationship between the offers and the asset values that resulted from the application of OLS methods (offer as a function of the asset value $(x+200) / 2)$.

${ }^{21}$ The buy rate is defined as the percentage of total pairs in which offerees decided to buy.
} 


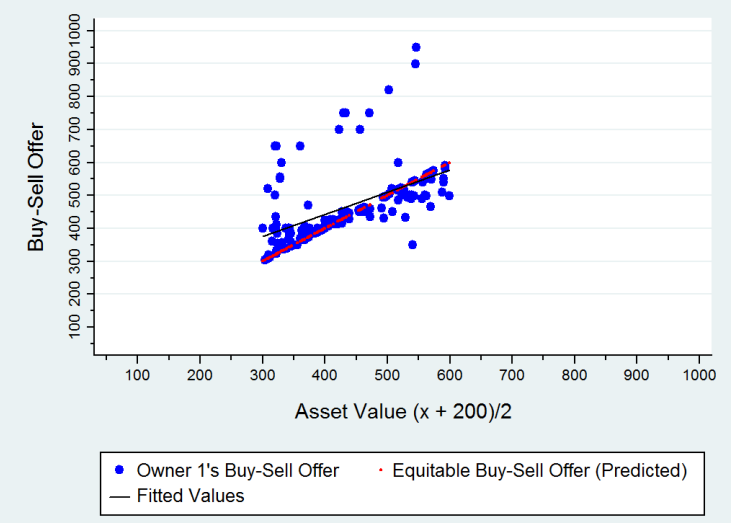

Figure 1: IO

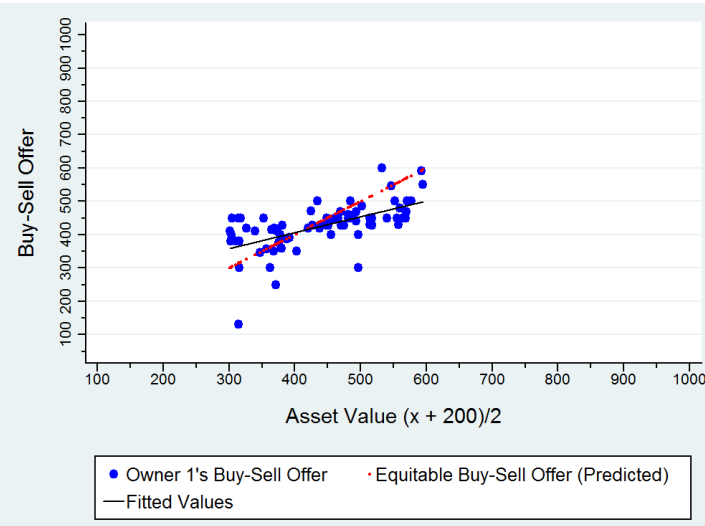

Figure 2: NO - Informed Offeror

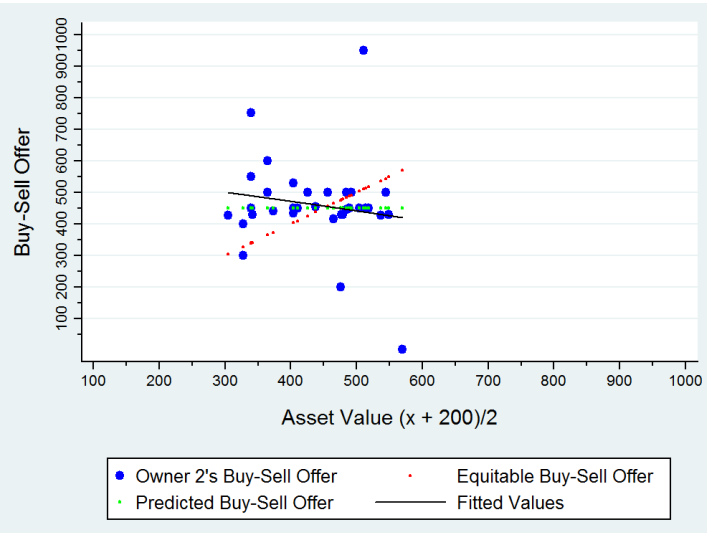

Figure 3: NO - Uninformed Offeror

when asset values were greater than or equal to 450 (71\% of the cases).

Our findings for the NO condition also indicate that the role of offeror was assigned to the informed and uninformed owners in 53 and $23 \%$ of the cases, respectively. As predicted by the theory, inefficiency (i.e., instances in which neither the informed nor the uninformed owners decided to be the offeror) occurred in the NO environment. The inefficiency rate (24\% of total cases) was higher than expected. Departures from the point predictions regarding gun-shy behavior were also observed. First, informed and uninformed owners were gun-shy in 33 and $63 \%$ of the cases, respectively. Second, inefficiency also occurred in case of asset values inside the interval $[408,492] .^{22}$

\footnotetext{
${ }^{22}$ Informed owners were gun shy inside this interval in $30 \%$ of the cases, and made offers outside the equilibrium interval in $65 \%$ of the cases.
} 
Finally, our data suggest that the NO environment negatively affected the uninformed offeror's mean payoff, reduced the equitable allocation rate, ${ }^{23}$ and increased the inefficiency rate (with respect to the IO treatment). ${ }^{24}$

\section{Efficient Outcomes}

In theory, inefficiency will occur in the NO environment under the mixed-strategy equilibrium. Our data indicate that inefficiency was present in $24 \%$ of the cases (rate significantly different from zero; $p$ - value $<.001) .{ }^{25}$ Inefficient outcomes reflect the gun-shy behavior of the informed and uninformed players. These findings support Hypothesis 1.

RESULT 1: The shotgun mechanism with an unassigned offeror generates inefficient outcomes.

\section{Equitable Outcomes}

We use regression analysis to test the effects of the NO environment on the likelihood of equitable outcomes and the uninformed owner's payoff. Our analysis involves robust standard errors which account for the possible dependence of observations within condition. We take pairs of conditions and estimate probit and OLS models. Each model includes a treatment dummy variable as its regressor and a round

\footnotetext{
${ }^{23}$ The equitable outcome rate is defined as the percentage of total pairs involving a 50-50 allocation (i.e., the uninformed owner's payoff is $50 \%$ of the sum of payoffs). For the NO condition, only consolidated ownership cases, i.e., cases in which one or both owners decided to be the offeror, are considered.

${ }^{24}$ Given the consistency of the aggregate data across rounds since early stages, we decided to include the 16 rounds in our analysis. The qualitative results still hold when only the last 8 rounds of play are considered. For exposition, rounded values (integers) are presented. The mean asset values (standard deviation in parentheses) under ownership consolidation are 431 (89) and 441 (83), for the case of the IO and NO conditions, respectively (the asset value differences between conditions were not statistically significant.

${ }^{25}$ To control for possible non-independence of observations, our binomial one-sided probability test used the data for the first actual round only (the inefficiency rate was equal to $33 \%$ in the first round; our findings also hold if we consider all rounds). The observed inefficient rate was marginally different from the theoretical rate ( $p$-value $=.083$, binomial one-sided test, first round data only; the results also hold if we consider all rounds).
} 
Table 1: Effects of the Shotgun Mechanism with an Unassigned Offeror on the Probability of Equitable Outcomes and the Uninformed Owner's Mean Payoff (Tests of Differences between Conditions)

\begin{tabular}{lcc}
\hline \hline Conditions & $\begin{array}{c}\text { Prob. Equitable Outcomes } \\
\text { (Marginal Effects) }\end{array}$ & $\begin{array}{c}\text { Uninf. Owner's Mean Payoff } \\
\text { (Coefficients) }\end{array}$ \\
\hline IO versus NO & $-0.047^{* * *}$ & $-63.535^{* * *}$ \\
& $(0.014)$ & $(15.203)$ \\
Observations & 240 & 288 \\
\hline
\end{tabular}

Note: The columns report the change in the probability of equitable outcomes and difference between the means (uninformed owner's payoff) due to the NO environment; marginal effects reported in case of the probit models; robust standard errors are in parentheses; ${ }^{* * *}$ denotes significance at the $1 \%$ level; observations correspond to number of pairs.

variable. ${ }^{26}$ Table 1 summarizes these findings.

Our results indicate that the NO environment significantly reduces the likelihood of equitable outcomes and the uninformed player's payoff, with respect to the informed offeror setting. ${ }^{27}$ In fact, as a result of the unassignment of the role of offeror, a lower likelihood of equitable outcomes is observed: $10 \mathrm{v}$. $28 \%$, for the $\mathrm{NO}$ and IO conditions, respectively. Similarly, the mean payoff for the uninformed players is lower under the NO condition: $389 \mathrm{v}$. 453, for the NO and IO conditions, respectively. These unequal outcomes might be attributed to the behavior of offerors and offerees in the NO - Uninformed Owner environment (23\% of the cases): Mode offer equal to 450, and strategic behavior of informed offerees who decided to sell when asset values were low (94\% of the cases) and to buy when asset values were high ( $71 \%$ of the cases). These findings provide strong support to Hypothesis 2.

RESULT 2: The shotgun mechanism with an unassigned offeror decreases the likelihood of equitable outcomes and the mean payoff for the uninformed owner (compared to the shotgun mechanism with an informed offeror).

\footnotetext{
${ }^{26}$ The dummy variable takes a value equal to 1 if the observation pertains to the NO condition, and a value equal to 0 otherwise. The round variable controls for learning effects across rounds. Data for the NO and IO are pooled (in case of the probit model, the NO data do not include cases in which neither owner 1 nor owner 2 decided to be the offeror).

${ }^{27}$ The variable round was not significant in any model.
} 


\section{Conclusion}

This article theoretically and experimentally studies shotgun mechanisms in a commonvalue setting with one-sided asymmetric information. Our experimental findings support our theory regarding the unequal and inefficient outcomes under the shotgun mechanism with an unassigned offeror. The implementation of the shotgun mechanism with an informed offeror, possible under ex post judicial resolution of deadlock, might preclude the occurrence of these undesirable outcomes.

\section{Acknowledgements}

We thank Tim Yuan for programming the software used in this study. Support from the National Science Foundation (Award No. SES-1155761) is gratefully acknowledged. Part of this research was conducted at Yale Law School and Harvard Law School, where Professor Landeo served as a Visiting Senior Research Scholar in Law.

\section{References}

Brooks, R., Landeo, C.M., and Spier, K.E., 2010. Trigger Happy or Gun Shy? Dissolving Common-Value Partnerships with Texas Shootouts. Rand J Econ 41, 649-673.

Carey, S.A., 2005. Buy/Sell Provisions in Real Estate Joint Venture Agreements. Real Property Probate Trust J 39, 651-709.

Che, Y-K. and Hendershott, T., 2008. How to divide the possession of a football? Econ Lett 99, 561-565.

Crawford, V.P., 1977. A Game of Fair Division. Rev Econ Studies 44, 253-247.

De Frutos, M.A. and Kittsteiner, T., 2008. Efficient Partnership Dissolution under Buy-Sell Clauses. Rand J Econ 39, 184-198.

Hauswald, R. and Hege, U., 2006. Ownership and Control in Joint Ventures. Manuscript. American University and HEC School of Management.

Kittsteiner, T., Ockenfels, A., and Trhal, N., 2012. Heterogeneity and Partnership Dissolution Mechanisms: Theory and Lab Evidence. Econ Lett 117, 394-396. 
Landeo, C.M. and Spier, K.E., forthcoming (a). Shotguns and Deadlocks. Yale J Regul.

Landeo, C.M. and Spier, K.E., forthcoming (b). Irreconcilable Differences: Judicial Resolution of Business Deadlocks. Univ Chic Law Rev. 
[Appendix: Instructions IO Condition.]

\section{PLEASE GIVE THIS MATERIAL TO THE EXPERIMENTER \\ AT THE END OF THE SESSION \\ INSTRUCTIONS}

This is an experiment in the economics of decision-making. Several academic institutions have provided the funds for this research.

In this experiment you will be asked to play an economic decision-making computer game. The experiment currency is the "token." The instructions are simple. If you follow them closely and make appropriate decisions, you may make an appreciable amount of money. At the end of the experiment you will be paid your total game earnings in CASH along with your participation fee. If you have any questions at any time, please raise your hand and the experimenter will go to your desk.

\section{SESSION AND PLAYERS}

The session is made up of 24 rounds. The first 8 rounds are practice rounds and will not be counted in the determination of your final earnings.

1) Before the beginning of each practice round, the computer will randomly form pairs of two people: One Player 1 and one Player 2. The roles will be randomly assigned. During the practice rounds, each person will play 4 times the roles of Player 1 and Player 2.

2) After the last practice round, 16 rounds will be played.

- Every participant will be randomly assigned a role. This ROLE WILL REMAIN THE SAME until the end of the session.

- At the beginning of each round, NEW PAIRS, one Player 1 and one Player 2 will be randomly formed.

You will not know the identity of your partner in any round. You know, however, that at the beginning of each round, NEW PAIRS of two people, Player 1 and Player 2 will be randomly formed. 


\section{ROUND STAGES}

\section{STAGE 1}

1) Player 1 and Player 2 jointly own a business. Each business partner owns $50 \%$ of the initial value of the business assets.

2) The computer randomly determines the initial value of the business assets and reveals this information ONLY to Player 1. Player 2 will NOT know the initial value of the business assets until the end of the round.

The initial values of the business assets can be any even integer number between 400 tokens and 1000 tokens. In other words, the initial value of the business assets can be 400 tokens, 402 tokens, ..., 998 tokens, or 1000 tokens. Each value is equally likely.

The Players have no choice over the initial value of the business assets. 


\section{STAGE 2}

1) Player 1 and Player 2 play a partnership-dissolution game.

- $\quad$ The business partnership will be dissolved. Then, the value of the business assets will increase by 200 tokens.

\section{PLAYER 1'S OFFER}

2) Player 1 makes a buy/sell price offer that Player 2 will use to buy Player 1's share of the business assets or to sell his/her share of the business assets to Player 1 . Player 1 can choose any price greater than or equal to 0 (no decimals).

\section{PLAYER 2'S RESPONSE}

3) After observing the price offer, Player 2 will decide whether to buy Player 1's share of the business assets at the proposed price, or to sell his/her share of the business assets to Player $\mathbf{1}$ at the proposed price.

- $\quad$ If Player 2 decides to BUY Player 1's share of the business assets, Player 2 transfers to Player 1 an amount of tokens equal to the price proposed. The business partnership is dissolved. Player 2 is now the sole owner of the business. The GAME ENDS.

Player 1's payoff = price proposed by Player 1

Player 2's payoff = initial value of the business assets +200 tokens - price proposed by Player 1

- If Player 2 decides to SELL his/her share of the business assets to Player 1, Player 1 transfers to Player 2 an amount of tokens equal to the price proposed. The business partnership is dissolved. Player 1 is now the sole owner of the business. The GAME ENDS.

Player 1's payoff = initial value of the business assets +200 tokens - price proposed by Player 1 Player 2’s payoff = price proposed by Player 1 


\section{ROUND PAYOFF}

The Payoff Table shows the round payoffs for Player 1 and Player 2, under the possible outcomes of the partnership-dissolution game.

\section{Payoff Table: PLAYER 1 MAKES A BUY/SELL PRICE OFFER}

\begin{tabular}{|c|c|}
\hline & $\begin{array}{l}\text { PAYOFFS IF PLAYER } 2 \text { DECIDES TO BUY HIS/HER PARTNER'S SHARE OF THE } \\
\text { BUSINESS ASSETS }\end{array}$ \\
\hline PLAYER 1 & price proposed by Player 1 \\
\hline PLAYER 2 & initial value of the business assets +200 tokens - price proposed by Player 1 \\
\hline & $\begin{array}{l}\text { PAYOFFS IF PLAYER } 2 \text { DECIDES TO SELL HIS/HER SHARE OF THE BUSINESS } \\
\text { ASSETS TO HIS/HER PARTNER }\end{array}$ \\
\hline PLAYER 1 & initial value of the business assets +200 tokens - price proposed by Player 1 \\
\hline PLAYER 2 & price proposed by Player 1 \\
\hline
\end{tabular}

\section{EXERCISES}

Two exercises related to the Payoff Table are presented below. Please fill the blanks.

\section{Exercise 1.}

Suppose that the initial value of the business assets is $\mathbf{C}$ tokens, Player $\mathbf{1}$ proposes a buy/sell price offer equal to $\mathbf{U}$ tokens, and Player 2 decides to sell his/her share of the business assets. Then, Player 1's payoff is equal to tokens, and Player 2's payoff is equal to tokens.

\section{Exercise 2.}

Suppose that the initial value of the business assets is $\mathbf{D}$ tokens, Player $\mathbf{1}$ proposes a buy/sell price offer equal to Y tokens, and Player 2 decides to buy his/her partner's share of the business assets. Then, Player 1's payoff is equal to tokens, and Player 2's payoff is equal to tokens. 


\section{SESSION PAYOFF}

The session earnings in tokens will be equal to the sum of payoffs for the 16 rounds. The session earnings in dollars will be equal to (session earnings in tokens)/427 (427 tokens $=1$ dollar). The total earnings in dollars will be equal to the participation fee plus the session earning in dollars.

\section{GAME SOFTWARE}

The game will be played using a computer terminal. You will need to enter your decisions by using the mouse. In some instances, you will need to wait until the other players make their decisions before moving to the next screen. Please be patient. There will be two boxes, displayed in the upper right-hand side of your screen, that indicate the "Round Number" and "Your Role."

Press the NEXT >> button to move to the next screen. Please, do not try to go back to the previous screen and do not close the browser: The software will stop working and you will lose all the accumulated tokens.

Next, the 8 PRACTICE ROUNDS will begin. After that, 16 rounds will be played. You can consult these instructions at any time during the session.

\section{THANKS FOR YOUR \\ PARTICIPATION IN THIS STUDY!!}

PLEASE GIVE THIS MATERIAL TO THE EXPERIMENTER AT THE END OF THE SESSION 
[Appendix: NO Instructions.]

\section{PLEASE GIVE THIS MATERIAL TO THE EXPERIMENTER \\ AT THE END OF THE SESSION INSTRUCTIONS}

This is an experiment in the economics of decision-making. Several academic institutions have provided the funds for this research.

In this experiment you will be asked to play an economic decision-making computer game. The experiment currency is the "token." The instructions are simple. If you follow them closely and make appropriate decisions, you may make an appreciable amount of money. At the end of the experiment you will be paid your total game earnings in CASH along with your participation fee. If you have any questions at any time, please raise your hand and the experimenter will go to your desk.

\section{SESSION AND PLAYERS}

The session is made up of 24 rounds. The first 8 rounds are practice rounds and will not be counted in the determination of your final earnings.

1) Before the beginning of each practice round, the computer will randomly form pairs of two people: One Player 1 and one Player 2. The roles will be randomly assigned. During the practice rounds, each person will play 4 times the roles of Player 1 and Player 2.

2) After the last practice round, 16 rounds will be played.

- $\quad$ Every participant will be randomly assigned a role. This ROLE WILL REMAIN THE SAME until the end of the session.

- At the beginning of each round, NEW PAIRS, one Player 1 and one Player 2 will be randomly formed.

You will not know the identity of your partner in any round. You know, however, that at the beginning of each round, NEW PAIRS of two people, Player 1 and Player 2 will be randomly formed. 


\section{ROUND STAGES}

\section{STAGE 1}

1) Player 1 and Player 2 jointly own a business. Each business partner owns $50 \%$ of the initial value of the business assets.

2) The computer randomly determines the initial value of the business assets and reveals this information ONLY to Player 1. Player 2 will NOT know the initial value of the business assets until the end of the round.

The initial values of the business assets can be any even integer number between 400 tokens and 1000 tokens. In other words, the initial value of the business assets can be 400 tokens, 402 tokens, ..., 998 tokens, or 1000 tokens. Each value is equally likely.

The Players have no choice over the initial value of the business assets. 


\section{STAGE 2}

1) Player 1 and Player 2 play a partnership-dissolution game.

- $\quad$ If the business partnership is dissolved, the value of the business assets increases by 200 tokens.

- If the business partnership is not dissolved, the value of business assets remains at its initial value.

\section{DECISION TO BECOME THE OFFEROR}

2) Player 1 and Player 2 simultaneously decide whether they want to become the OFFEROR, i.e., whether they want to make a buy/sell price offer to the other player, that the other player will use to buy the offeror's share of the business assets or to sell his/her share of the business assets to the offeror.

- If BOTH players decide they want to become the OFFEROR, then the computer randomly determines which player will become the OFFEROR. Each player has an equal chance of becoming the offeror.

- If only ONE player decides he/she wants to become the OFFEROR, then this player becomes the OFFEROR.

- If NEITHER PLAYER 1 NOR PLAYER 2 decides he/she wants to become the OFFEROR, then the business partnership is not dissolved. The GAME ENDS. Each player receives a payoff equal to half of the initial value of the business assets. 


\section{IF PLAYER 1 BECOMES THE OFFEROR}

\section{PLAYER 1'S OFFER}

3) Player 1 makes a buy/sell price offer that Player 2 will use to buy Player 1's share of the business assets or to sell his/her share of the business assets to Player 1. Player 1 can choose any price greater than or equal to 0 (no decimals).

\section{PLAYER 2'S RESPONSE}

4) After observing the price offer, Player 2 will decide whether to buy Player 1's share of the business assets at the proposed price, or to sell his/her share of the business assets to Player $\mathbf{1}$ at the proposed price.

- $\quad$ If Player 2 decides to BUY Player 1's share of the business assets, Player 2 transfers to Player 1 an amount of tokens equal to the price proposed. The business partnership is dissolved. Player 2 is now the sole owner of the business. The GAME ENDS.

Player 1's payoff = price proposed by Player 1

Player 2's payoff = initial value of the business assets +200 tokens - price proposed by Player $\mathbf{1}$

- If Player 2 decides to SELL his/her share of the business assets to Player 1, Player 1 transfers to Player 2 an amount of tokens equal to the price proposed. The business partnership is dissolved. Player 1 is now the sole owner of the business. The GAME ENDS.

Player 1's payoff = initial value of the business assets +200 tokens - price proposed by Player 1 Player 2’s payoff = price proposed by Player 1 


\section{IF PLAYER 2 BECOMES THE OFFEROR}

\section{PLAYER 2'S OFFER}

3) Player 2 makes a buy/sell price offer that Player 1 will use to buy Player 2's share of the business assets or to sell his/her share of the business assets to Player 2. Player 2 can choose any price greater than or equal to 0 (no decimals).

\section{PLAYER 1'S RESPONSE}

4) After observing the price offer, Player 1 will decide whether to buy Player 2's share of the business assets at the proposed price, or to sell his/her share of the business assets to Player 2 at the proposed price.

- If Player 1 decides to BUY Player 2's share of the business assets, Player 1 transfers to Player 2 an amount of tokens equal to the price proposed. The business partnership is dissolved. Player $\mathbf{1}$ is now the sole owner of the business. The GAME ENDS.

Player 1's payoff $=$ initial value of the business assets +200 tokens - price proposed by Player 2 Player 2’s payoff = price proposed by Player 2

- If Player 1 decides to SELL his/her share of the business assets to Player 2, Player 2 transfers to Player 1 an amount of tokens equal to the price proposed. The business partnership is dissolved. Player 2 is now the sole owner of the business. The GAME ENDS.

Player 1's payoff = price proposed by Player 2

Player 2's payoff = initial value of the business assets +200 tokens - price proposed by Player 2 


\section{IF NEITHER PLAYER 1 NOR PLAYER 2 BECOMES THE OFFEROR}

The GAME ENDS.

Player 1's payoff = initial value of the business assets/2

Player 2's payoff = initial value of the business assets/2 


\section{ROUND PAYOFF: PLAYER 1 BECOMES THE OFFEROR}

The Payoff Table shows the round payoffs for Player 1 and Player 2, under the possible outcomes of the partnership-dissolution game.

\section{Payoff Table: PLAYER 1 MAKES A BUY/SELL PRICE OFFER}

\begin{tabular}{|l|l|}
\hline & \multicolumn{1}{|c|}{$\begin{array}{c}\text { PAYOFFS IF PLAYER 2 DECIDES TO BUY HIS/HER PARTNER'S SHARE OF THE } \\
\text { BUSINESS ASSETS }\end{array}$} \\
\hline PLAYER 1 & price proposed by Player 1 \\
\hline PLAYER 2 & initial value of the business assets + 200 tokens - price proposed by Player 1 \\
\hline PAYOFFS IF PLAYER 2 DECIDES TO SELL HIS/HER SHARE OF THE BUSINESS \\
ASSETS TO HIS/HER PARTNER \\
\hline PLAYER 1 & initial value of the business assets + 200 tokens - price proposed by Player 1 \\
\hline PLAYER 2 & price proposed by Player 1 \\
\hline
\end{tabular}

\section{EXERCISES}

Two exercises related to the Payoff Table are presented below. Please fill the blanks.

Exercise 1.

Suppose that the initial value of the business assets is $\mathbf{C}$ tokens, Player $\mathbf{1}$ proposes a buy/sell price offer equal to $\mathbf{U}$ tokens, and Player 2 decides to sell his/her share of the business assets. Then, Player 1's payoff is equal to tokens, and Player 2's payoff is equal to tokens.

\section{Exercise 2.}

Suppose that the initial value of the business assets is D tokens, Player 1 proposes a buy/sell price offer equal to $\mathbf{Y}$ tokens, and Player 2 decides to buy his/her partner's share of the business assets. Then, Player 1's payoff is equal to tokens, and Player 2's payoff is equal to tokens. 


\section{ROUND PAYOFF: PLAYER 2 BECOMES THE OFFEROR}

The Payoff Table shows the round payoffs for Player 1 and Player 2, under the possible outcomes of the partnership-dissolution game.

Payoff Table: PLAYER 2 MAKES A BUY/SELL PRICE OFFER

\begin{tabular}{|c|c|}
\hline & $\begin{array}{c}\text { PAYOFFS IF PLAYER } 1 \text { DECIDES TO BUY HIS/HER PARTNER'S SHARE OF THE } \\
\text { BUSINESS ASSETS }\end{array}$ \\
\hline PLAYER 1 & initial value of the business assets +200 tokens - price proposed by Player 2 \\
\hline PLAYER 2 & price proposed by Player 2 \\
\hline & $\begin{array}{c}\text { PAYOFFS IF PLAYER } 1 \text { DECIDES TO SELL HIS/HER SHARE OF THE BUSINESS } \\
\text { ASSETS TO HIS/HER PARTNER }\end{array}$ \\
\hline PLAYER 1 & price proposed by Player 2 \\
\hline PLAYER 2 & assets +200 tokens - price proposed by Player 2 \\
\hline
\end{tabular}

\section{EXERCISES}

Two exercises related to the Payoff Table are presented below. Please fill the blanks.

\section{Exercise 1.}

Suppose that the initial value of the business assets is $\mathbf{C}$ tokens, Player $\mathbf{2}$ proposes a buy/sell price offer equal to W tokens, and Player 1 decides to sell his/her share of the business assets. Then, Player 1's payoff is equal to tokens, and Player 2's payoff is equal to tokens.

\section{Exercise 2.}

Suppose that the initial value of the business assets is $\mathbf{D}$ tokens, Player $\mathbf{2}$ proposes a buy/sell price offer equal to $\mathbf{Z}$ tokens, and Player 1 decides to buy his/her partner's share of the business assets. Then, Player 1's payoff is equal to tokens, and Player 2's payoff is equal to tokens. 


\section{ROUND PAYOFF: NEITHER PLAYER 1 NOR PLAYER 2 BECOMES THE OFFEROR}

The Payoff Table shows the round payoffs for Player 1 and Player 2, under the possible outcomes of the partnership-dissolution game.

Payoff Table: NEITHER PLAYER 1 NOR PLAYER 2 DECIDE TO BE THE OFFER0R

Player 1's payoff = initial value of the business assets/2

Player 2's payoff = initial value of the business assets $/ 2$

\section{EXERCISES}

Two exercise related to the Payoff Table is presented below. Please fill the blanks.

Exercise 1.

Suppose that the initial value of the business assets is $\mathbf{C}$ tokens. Neither Player $\mathbf{1}$ nor Player $\mathbf{2}$ decide to be the OFFEROR. Then, Player 1's payoff is equal to tokens, and Player 2's payoff is equal to tokens.

\section{Exercise 2.}

Suppose that the initial value of the business assets is D tokens. Neither Player 1 nor Player 2 decide to be the OFFEROR. Then, Player 1's payoff is equal to tokens, and Player 2's payoff is equal to tokens. 


\section{SESSION PAYOFF}

The session earnings in tokens will be equal to the sum of payoffs for the 16 rounds. The session earnings in dollars will be equal to (session earnings in tokens)/427 (427 tokens $=1$ dollar). The total earnings in dollars will be equal to the participation fee plus the session earning in dollars.

\section{GAME SOFTWARE}

The game will be played using a computer terminal. You will need to enter your decisions by using the mouse. In some instances, you will need to wait until the other players make their decisions before moving to the next screen. Please be patient. There will be two boxes, displayed in the upper right-hand side of your screen, that indicate the "Round Number" and "Your Role."

Press the NEXT >> button to move to the next screen. Please, do not try to go back to the previous screen and do not close the browser: The software will stop working and you will lose all the accumulated tokens.

Next, the 8 PRACTICE ROUNDS will begin. After that, 16 rounds will be played. You can consult these instructions at any time during the session.

\section{THANKS FOR YOUR \\ PARTICIPATION IN THIS STUDY!! \\ PLEASE GIVE THIS MATERIAL TO THE EXPERIMENTER AT THE END OF THE SESSION}


[Supplementary Material (Not for Publication).]

\title{
Shotgun Mechanisms for Common-Value Partnerships: The Unassigned-Offeror Problem
}

\author{
Claudia M. Landeo*and Kathryn E. Spier ${ }^{\dagger}$
}

\section{Appendix}

This appendix first presents the proofs for Proposition $1 .^{1}$ Second, it includes additional data material.

\section{PROOF OF PROPOSITION 1}

(Informed Offeror) If Owner 1's equilibrium proposal is $p_{1}(x)=\frac{x+a}{2}$ then Owner 2 is indifferent between buying and selling, since Owner 2's payoff would be $\frac{x+a}{2}$ in either case. Suppose Owner 2 randomizes $50-50$ between buying and selling for all price offers. Suppose that Owner 1 is of type $x$. Owner 1's expected payoff from offering a price $p_{1}$ would be $\frac{1}{2}\left(x+a-p_{1}\right)+\frac{1}{2}\left(p_{1}\right)=\frac{x+a}{2}$. This is independent of $p_{1}$ so Owner 1 of type $x$ is indifferent over the level of the offer and offering $p_{1}(x)=\frac{x+a}{2}$ is therefore incentive compatible. Thus, the strategies for Owner 1 outlined in the Proposition constitute a perfect Bayesian equilibrium.

(Uninformed Offeror) An offer by Owner 2, $p_{2}$, creates a cutoff $y=2 p_{2}-a$ where Owner 1 sells his stake to Owner 2 for $p_{2}$ if $x<y$ and Owner 1 buys Owner 2's stake for $p_{2}$ if $x \geq y$. So Owner 2's problem may be written as choosing the cutoff $y$ and the corresponding price $p_{2}=\frac{y+a}{2}$ to maximize his payoff:

$$
\int_{x_{L}}^{y}\left(x+a-\frac{y+a}{2}\right) d F(x)+\int_{y}^{x_{H}}\left(\frac{y+a}{2}\right) d F(x) .
$$

\footnotetext{
*University of Alberta Economics Department.

$\dagger$ Harvard Law School and NBER.

${ }^{1}$ These results follow from Propositions 1 and 2 presented in our previous work (Brooks et al.,
} 2010). 
Table A1: Descriptive Statistics

\begin{tabular}{|c|c|c|}
\hline & $\mathrm{IO}$ & NO \\
\hline Informed Owner's Price ${ }^{(a)}$ & $\begin{array}{c}463 \\
(113)\end{array}$ & $\begin{array}{l}428 \\
(68)\end{array}$ \\
\hline Uninformed Owner's Price ${ }^{(a)}$ & $\begin{array}{l}- \\
-\end{array}$ & $\begin{array}{c}461 \\
(146)\end{array}$ \\
\hline Informed Owner's Payoff & $\begin{array}{c}410 \\
(138)\end{array}$ & $\begin{array}{c}445 \\
(144)\end{array}$ \\
\hline Uninformed Owner's Payoff & $\begin{array}{c}453 \\
(132)\end{array}$ & $\begin{array}{c}389 \\
(125)\end{array}$ \\
\hline Equitable Outcome Rate & 28 & 10 \\
\hline Inefficiency Rate & 0 & 24 \\
\hline Asset Value ${ }^{(b)}$ & $\begin{array}{l}431 \\
(89)\end{array}$ & $\begin{array}{l}441 \\
(83)\end{array}$ \\
\hline Observations $^{(c)}$ & 144 & 144 \\
\hline
\end{tabular}

Note: ${ }^{(a)}$ Mean prices are presented; ${ }^{(b)}$ mean asset values per owner under ownership consolidation are presented; ${ }^{(c)}$ sample sizes correspond to the number of pairs for the 16 rounds; standard deviations are presented in parentheses.

The derivative of this expression with respect to $y$ equals $\frac{1}{2}-F(y)$. Setting the derivative equal to zero confirms that $y=\bar{x}$ and therefore $p_{2}=\frac{\bar{x}+a}{2}$. Player 2's payoff is $\int_{x_{L}}^{\bar{x}}(x+a) d F(x)=\frac{1}{2} E(x+a \mid x \leq \bar{x})$.

\section{ADDITIONAL DATA MATERIAL}

Table A1 provides the descriptive statistics. ${ }^{2}$ Information about the mean prices and payoffs for informed and uninformed owners is included. The equitable outcome rate is defined as the percentage of total pairs involving a 50-50 allocation (i.e., the uninformed owner's payoff is $50 \%$ of the sum of payoffs (for the unassigned-offeror condition (NO), only consolidated ownership cases, i.e., cases in which one or both owners decide to be the offeror, are considered). The inefficiency rate is defined as the percentage of total pairs in which inefficient joint ownership is preserved (i.e., the percentage of total cases in which neither the informed nor the uninformed owner decided to be the offeror). Mean asset values per owner under ownership consolidation are presented. ${ }^{3}$

\footnotetext{
${ }^{2}$ Given the consistency of the aggregate data across rounds since early stages, we decided to include the 16 rounds in our analysis. The qualitative results still hold when only the last 8 rounds of play are considered. For exposition, rounded values (integers) are presented.

${ }^{3}$ The asset value differences between conditions were not statistically significant.
} 